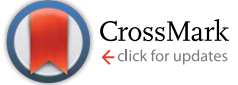

Cite this: RSC Adv., 2014, 4, 64649
Received 26th September 2014 Accepted 17th November 2014

DOI: 10.1039/c4ra11319e

www.rsc.org/advances

\section{Mechanical and electrical properties of high performance MWCNT/polycarbonate composites prepared by an industrial viable twin screw extruder with back flow channel†}

\author{
Arun Singh Babal, $\$^{\mathrm{a}}$ Ravi Gupta, $\$^{\mathrm{a}}$ Bhanu Pratap Singh, ${ }^{\text {*a }}$ Vidya Nand Singh, ${ }^{\mathrm{b}}$ \\ Sanjay R. Dhakate ${ }^{a}$ and Rakesh B. Mathur ${ }^{a}$
}

High performance multiwall carbon nanotube (MWCNT) reinforced polycarbonate (PC) composites were prepared using an industrially viable fast dispersion process by a micro twin screw extruder with back flow channel and their mechanical and electrical properties were investigated for EMI shielding applications. A uniformly dispersed MWCNT/PC composite system was observed through SEM and TEM investigations. Incorporation of a small amount of MWCNT (2 wt\%) led to enhancements in the tensile strength (up to $79.6 \mathrm{MPa}$ ) and flexural strength (up to $110 \mathrm{MPa}$ ), which were equivalent to $19.6 \%$ and $14.6 \%$ increases over the neat PC. The effect of MWCNTs on the failure mechanism of the PC under tensile loading showed a ductile to brittle transition with increasing concentration of MWCNTs. The results of enhanced mechanical properties were well supported by micro Raman spectroscopic studies. In addition to the mechanical properties, significant improvement in the electrical conductivity $\left(0.01 \mathrm{~S} \mathrm{~cm}^{-1}\right.$ at $10 \mathrm{wt} \%$ MWCNT) of these composites was observed which yielded the EMI shielding of $-27.2 \mathrm{~dB}$ in the Ku band suggesting their possible use as a high strength EMI shielding material.

\section{Introduction}

To fulfill the growing demand of plastic industries, polymer composites having lighter weight, higher corrosion resistance and superior strength with improved electrical properties are being extensively studied. ${ }^{\mathbf{1 , 2}}$ Polymer composites are preferred over metal composites due to their processing advantages. Since the discovery of carbon nanotubes (CNT), they serve as an extremely excellent candidate for reinforcement due to their astounding mechanical and electrical properties. ${ }^{3-15}$ Polycarbonate (PC) is an established engineering thermoplastic matrix which demonstrates a variety of characteristics for a wide range of applications and therefore is more appealing than other polymers due to its concomitant high mechanical properties, good dimensional stability, thermal stability, transparency, ease of processing, low cost and its thermoforming properties. ${ }^{16-18}$ Prominent uses of PC are in the areas of

\footnotetext{
${ }^{a}$ Physics and Engineering of Carbon, CSIR-National Physical Laboratory, Dr K. S. Krishnan Road, New Delhi-110 012, India. E-mail: bps@nplindia.org; bpsingh2k4@ yahoo.com; Fax: +91-11-45609310; Tel: +91-11-45608460

${ }^{b}$ Electron \& Ion Microscopy Section, CSIR-National Physical Laboratory, Dr K. S. Krishnan Road, New Delhi-110 012, India

$\dagger$ Electronic supplementary information (ESI) available. See DOI: 10.1039/c4ra11319e

$\ddagger$ Both authors contributed equally.
}

automotive, aerospace, data storage and construction industries (mainly in dome light, sound walls and security components).

Homogeneous dispersion of CNT in polymer host is a key issue for making CNT/PC composite. At present, three methods are commonly used to blend CNT in the polymer matrix: (i) melt mixing of CNT in the polymer matrix, ${ }^{19}$ (ii) film casting of suspended CNT in polymers, ${ }^{20}$ (iii) in situ polymerization of CNTpolymer monomer mixtures. Melt mixing is one of the most preferred method due to its being industrially viable. Tendency of CNTs to form aggregates can be minimized by introducing appropriate shear force during melt mixing.

In past decades, several studies have discussed mechanical properties of CNT/PC composites. In almost all the studies, it has been reported that the modulus increases with CNT content. But, the increment in strength with CNT content was not consistent. In some cases even it was reported that mechanical strength decreases with the increase of CNT concentration. Previous studies suggested that the tensile/ flexural strength of composites largely depend on CNTs alignment, it's surface modification (functionalization), dispersion and interaction with polymers. ${ }^{21-24}$ Eitan et al. prepared multiwall carbon nanotube (MWCNT)/PC composites by solvent casting followed by DACA mini-injection molding method. ${ }^{25}$ In that study maximum tensile strength 
of $70 \mathrm{MPa}$ was achieved with $5 \mathrm{wt} \%$ MWCNT incorporation and overall $18.6 \%$ increment over pure PC. It should be noted that solvent casting has several disadvantages, for example, use of toxic solvent, non-uniformity of film thickness, nonuniform drying, high cost and non-continuous production which leads to its industrially non-viability. Kum et al. reported $10.4 \%$ enhancement in the tensile strength of $2.5 \mathrm{wt} \%$ MWCNT loaded sample over pure PC using melt mixing followed by compression molding. ${ }^{26}$ Further addition of MWCNT lead to decrease in strength. Chen et al. showed that composite with 1 wt\% MWCNT content have $4.5 \%$ higher tensile strength than pure PC prepared by co-rotating intermeshing twin-screw compounding extruder (TSSJ-25) followed by injection molding. ${ }^{22}$ King et al. studied 1-8 wt\% MWCNT loaded PC composites prepared by extruder (Model ZSE 27) followed by injection molding to analyze both flexural and tensile properties. ${ }^{24}$ They observed maximum tensile strength of $62 \mathrm{MPa}$, an overall improvement of $3.3 \%$ over pure PC for $2 \mathrm{wt} \%$ MWCNT samples. For more than $2 \mathrm{wt} \%$ MWCNT strength decreased. 8.7\% increment in the flexural strength is observed for $6 \mathrm{wt} \%(125 \mathrm{MPa})$ MWCNT incorporation over pure PC (115 $\mathrm{MPa})$. Fornes et al. observed that aligned MWCNT/PC composites show high modulus and strength with increase in CNT content. ${ }^{23}$ Pande et al. studied composite samples (fabricated using solvent casting method) comprising CNT content up to $20 \mathrm{wt} \%{ }^{27}$ They reported maximum yield stress for $2 \mathrm{wt} \%$ MWCNT sample (an overall improvement of $18.2 \%$ over pure PC). Further addition lead to decrease in yield stress but modulus show enhancement with addition of MWCNT. These relevant studies on mechanical properties of MWCNT/PC composite suggest that the improvement in strength is not significant. The process used for preparation of the composite is mostly solvent casting followed by extrusion and injection moulding. These process are not industrial viable. Herein, we report the preparation of uniformly dispersed MWCNT/PC composites using industrially viable melt mixing method using twin screw extruder with back flow channel.

Additionally, CNTs have unique electrical properties that can be utilized to fulfill the growing demand for electromagnetic interference (EMI) shielding material in electronics industry. At present, EMI is one of the critical issue of modern society. Polymer composites with high mechanical properties and good EMI shielding in the range of 12-18 GHz (Ku-band) have momentous application in commercial, military, satellite communication and electronic device. Various electronic devices emit electromagnetic signals that can impede other devices, e.g. electro-magnetic waves (EMW) created in the airplane cockpit can be reduced by using material with high strength, low density and good EMI shielding efficiency. ${ }^{28}$ As for the EMI shielding properties, several studies are conducted in the area of MWCNT/polymer composite. EMI shielding effectiveness (SE) predominantly depends upon the conductivity of reinforcement, dielectric constant and aspect ratio. ${ }^{29}$ Arjmand et al. observed the EMI shielding properties of MWCNT/PC composites in X-band and attained EMI SE value of about $25 \mathrm{~dB}$ for compression molded $5 \mathrm{wt} \% \mathrm{MWCNT} /$
PC composites. ${ }^{30}$ Pande et al. studied the EMI shielding properties of high pressured and low pressured compression molded MWCNT/PC composites in X-band. ${ }^{27}$ They observed shielding effectiveness (SE) of about $21 \mathrm{~dB}$ for high pressured $10 \mathrm{wt} \% \mathrm{MWCNT} / \mathrm{PC}$ and $35 \mathrm{~dB}$ for low pressured $10 \mathrm{wt} \%$ MWCNT/PC. In addition to $\mathrm{PC}$, some other engineering plastic has also been studied for EMI shielding. Wang et al. ${ }^{31}$ fabricated composites based on poly(ether ether ketone) (PEEK) in which PES poly(ether sulfone) wrapped MWCNTs were used as a filler, by using melt-blending technique. They observed that PES wrapped-MWCNT-PEEK composites shows effective absorbing shields in $\mathrm{X}, \mathrm{Ku}$ and $\mathrm{K}$ band frequency ranges. In the Ku band frequency range, the average shielding effectiveness (SE) of pure PEEK was $20 \mathrm{~dB}$, which increased up to the average SE of $40 \mathrm{~dB}$ and $55 \mathrm{~dB}$ after incorporation of $7 \mathrm{wt} \%$ and $12 \mathrm{wt} \%$ wrapped-MWCNTs, respectively. PEEK is a super engineering plastic which is generally used for some specific application where cost is not a big issue. On the other hand PC is cost effective engineering plastic compared to PEEK. ${ }^{31}$

This paper is mainly related to the study of effect of MWCNT on the mechanical and electrical properties of MWCNT/PC composites prepared by mini twin screw extruder with back flow channel.

\section{Experimental}

\section{Material}

In this study, polycarbonate based bisphenol A (PC) was obtained from Bayer Material Science (MAKROLON® 2407) and used as a host material. MWCNTs were synthesized by utilizing catalytic chemical vapor deposition (CCVD) technique in which toluene $\left(\mathrm{C}_{6} \mathrm{H}_{5} \mathrm{CH}_{3}, 99 \%\right.$ purity) was thermally decomposed in a $18 \mathrm{~cm}$ long constant heating zone in the presence of ferrocene $\left(\mathrm{C}_{10} \mathrm{H}_{10} \mathrm{Fe}\right.$, purity $\left.99 \%\right)$. This solution $(0.077 \mathrm{~g}$ ferrocene in $1 \mathrm{ml}$ toluene) was feeded into heated quartz tube at a feeding rate of $10 \mathrm{ml} \mathrm{h}^{-1}$ in an inert atmosphere. Further details are given elsewhere. $^{32}$

\section{Fabrication of MWCNT/polycarbonate composites}

Since melt mixing have several advantages over solvent casting and in situ polymerization, HAAKE MiniLab II Micro Compounder was used for dispersion of MWCNT in PC and mini injector was employed for injection molding to fabricate MWCNT/PC composites. This compounder has capacity of $5 \mathrm{~g}$ or $7 \mathrm{~cm}^{3}$ and has two conical co-rotating screws with a bypass pathway for the flow of material which allow proper dispersion. After the preferred mixing time $(3 \mathrm{~min})$, melt was passed through a die (by opening pressure valves) kept in the cylinder of injection molding machine heated at $290{ }^{\circ} \mathrm{C}$. The temperatures of the compounder $\left(250^{\circ} \mathrm{C}\right)$, the injector $\left(290^{\circ} \mathrm{C}\right)$ and mixing time ( $3 \mathrm{~min}$.) were optimized by repeated production of composites. Rotation speed of screw was set to $100 \mathrm{rpm}$. Prior to incorporation of MWCNTs into the PC matrix, polymer was dried in the vacuum oven at $100{ }^{\circ} \mathrm{C}$ for $24 \mathrm{~h}$ to remove the moisture trapped in polymer beads. 
Different amount of MWCNTs $(0.5 \%, 1 \%, 2 \%, 5 \%$ and $10 \%)$ was used as reinforcement into PC matrix. After the mixing of MWCNTs in polycarbonate for preferred time, it was extruded and material was taken into the cylinder and injected into the mould by applying pressure through the cylinder piston. Basically conventional twin screw extruder does not have the back flow channel. Conventional twin screw extruder have only a single path for the flow the materials. Therefore, residence time for mixing is very small. Residence time in of conventional twin screw extruder can also be increased by decreasing the speed of screws which is not favorable for better mixing. In the twin screw extruder with back flow channel, residence time can be changed without compromising the speed of the screws. Therefore, the twin screw extruder with back flow channels can enable uniform dispersion of MWCNT in polymer matrix.

In this study, two sorts of mould are used: (i) ASTM D638, and (ii) ASTM D790. There are different parameter of mini injector which have significant effect on composite fabrication process, including pre pressure, post pressure, time and cylinder temperature that can be varied. ${ }^{33}$

These parameters were optimized for polycarbonate polymer by repeated composite fabrication. Time of injection of material into the mold was kept $7 \mathrm{~s}$ by exerting pre pressure and post pressure of
650 bar and 900 bar, respectively. The whole process is elucidated in Fig. 1.

\section{Characterization}

\section{Morphological characterization}

High resolution transmission electron microscope (HRTEM) was used for the exploration of morphological properties of MWCNT/PC nanocomposites. HRTEM studies were carried out using Technai G20-stwin, operated at $300 \mathrm{kV}$ having point resolution of $0.2 \mathrm{~nm}$ and lattice resolution of $0.14 \mathrm{~nm}$.

\section{Mechanical property studies}

Flexural (ASTM D790) and tensile (ASTM D638) properties of MWCNT/PC composites were probed by Instron universal testing machine (model 4411). The dog bone shape tensile specimen has the dimension of $15.00 \mathrm{~mm} \times 3.00 \mathrm{~mm} \times 3.27$ $\mathrm{mm}$ (length $\times$ wide $\times$ thick) concomitant with total length of 60 $\mathrm{mm}$ and flexural specimen has the dimension of $69.75 \mathrm{~mm} \times$ $12.6 \mathrm{~mm} \times 3.27 \mathrm{~mm}$ (length $\times$ wide $\times$ thick). The gauge length of the samples was fixed for both flexural and tensile measurement which was 50 and $15 \mathrm{~mm}$, respectively. The crosshead speed was $1 \mathrm{~mm} \mathrm{~min}^{-1}$.

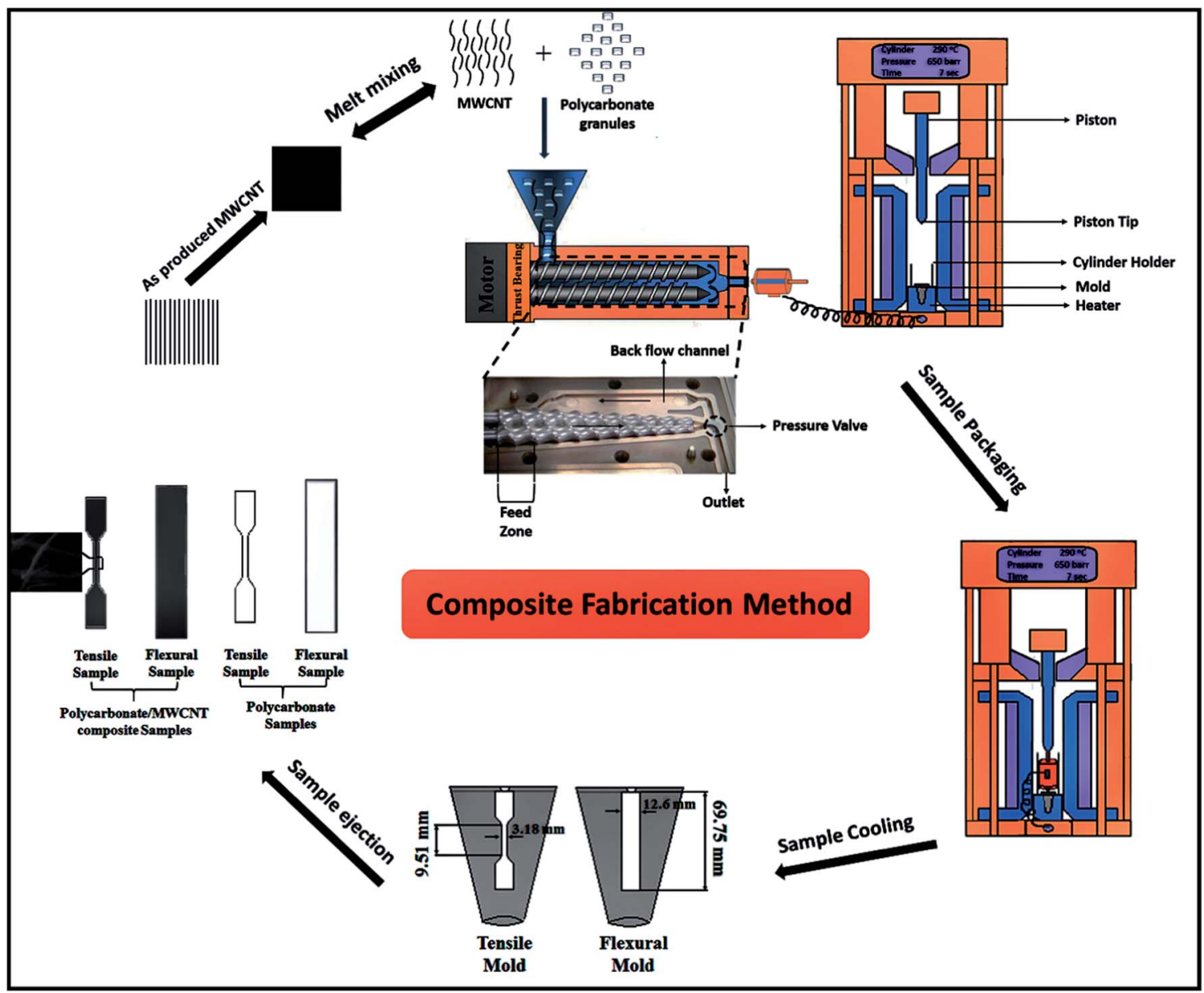

Fig. 1 Schematic diagram for preparation of MWCNT/polycarbonate composites by micro twin screw extrusion followed by injection molding. 


\section{Electrical conductivity measurements}

The volume resistivity was measured on molded flexural samples by 4-point method. The composite specimens were cut into the dimensions of $13 \times 7 \times 3 \mathrm{~mm}^{3}$ using the diamond cutter. Before measurements the specimens were cleaned with ethanol. Voltage drop was measured with respect to the current applied to the specimen. For this purpose, Keithley SCS 4200 machine was used.

\section{EMI shielding measurements}

The EMI shielding measurements of MWCNT/PC composites were carried out in the Ku-band (12.4-18 GHz). The specimen under examination was sandwiched between two Ku-band waveguide sections, which were attached to separate ports of an Agilent E8362B Vector Network Analyzer. It guides signal to the sandwiched sample, both the reflected and transmitted signals were measured by the VNA. EMI shielding effectiveness is expressed in $\mathrm{dB}$ units and is defined by: ${ }^{\mathbf{2 0 , 2 8 , 3 4}}$

$$
\mathrm{SE}=10 \log \left(P_{\text {in }} / P_{\text {out }}\right)=20 \log \left(E_{\text {in }} / E_{\text {out }}\right)=20 \log \left(H_{\text {in }} / H_{\text {out }}\right)
$$

where $P_{\text {in }}$ is incident power, $P_{\text {out }}$ is transmitted power and $E$ and $H$ are the value of electric and magnetic field strength of the EMW, respectively.

\section{Raman spectroscopy}

Raman spectra of composite specimens were collected using the Renishaw inVia Raman Spectrometer, UK, with excitation laser source of $785 \mathrm{~nm}$ wavelength. The Raman spectra were recorded in the $100 \mathrm{~cm}^{-1}$ to $3000 \mathrm{~cm}^{-1}$ range with $5 \mathrm{~mW}$ laser power and $10 \mathrm{~s}$ of exposure time (in perpendicular direction of the melt flow).

\section{Results and discussion}

\section{Mechanical properties of the composite samples}

Tensile properties of MWCNT/PC composite sample. Incorporation of MWCNTs has significant effect on the behavior of the polymer composite such as transition from ductile to brittle behavior. Higher amount of MWCNT enhances the brittle behavior. Fig. 2 shows the stress-strain curve of MWCNT/PC composite specimens. The effect of MWCNTs amount on mechanical properties were restrained up to $10 \mathrm{wt} \%$ MWCNT. By comparing the stress values of different composite samples, role of MWCNTs can be analyzed. At higher strain values (after the yield point of pure PC) composite samples show higher stress value, i.e. 56.4 MPa to $61.33 \mathrm{MPa}$ for 2 to $10 \mathrm{wt} \% \mathrm{MWCNT} / \mathrm{PC}$ composites as compared to the pure PC (48.8 MPa) (Fig. 2(b)). The composite is stiff and does not undergo yield beyond certain limit and maintains its mechanical properties.

Effect of MWCNTs on the elastic modulus and tensile strength (ultimate tensile strength (UTS)) of PC matrix are shown in Fig. 3. The $10 \mathrm{wt} \% \mathrm{MWCNT} / \mathrm{PC}$ composite shows $15.33 \%$ (1587 MPa) enhancement in elastic modulus over pure PC (1376 MPa) (Fig. 3(a)). Increased amount of MWCNT enhances the elastic modulus but hinders the polymer mobility by enhancing its stiffness. The trend observed in the elastic modulus data is also reported by other researchers. ${ }^{24,25,35}$

The ultimate tensile strength of the composite samples increased with incorporation of MWCNT up to $2 \mathrm{wt} \%$. The average UTS increased by $19.6 \%(79.6 \mathrm{MPa})$ at $2 \mathrm{wt} \%$ loading as compared to the PC polymer (Fig. 3(b)). Further increase in MWCNT amount leads to slight decrease in the tensile strength due to the agglomeration of MWCNT. Agglomeration can lessen the reinforcement effect of MWCNTs by ineffectively transferring the external load, leading to reduction in strength of composite material. ${ }^{31,36}$

There is a sudden decline in the elongation at the breaking point for the $2 \mathrm{wt} \% \mathrm{MWCNT} / \mathrm{PC}$ composite sample (see Fig. 3(c)). The region between 1 and $2 \mathrm{wt} \% \mathrm{MWCNT} / \mathrm{PC}$ composite can be considered as a transition zone in which composite with below 1 wt $\%$ MWCNT concentration shows ductile behavior while with above $2 \mathrm{wt} \%$ shows brittle behavior. This has been reported by many researchers. ${ }^{22,24,35}$ This is also evident from images of failed MWCNT/PC composite samples (Fig. 3(d)). Fracture point of composite samples move away from the middle portion of the neck with increased amount of MWCNT content which support the conclusion; increase in brittle behavior of composite with increase in MWCNT amount. All tensile property parameters are given in Table S1 (see $\operatorname{ESI} \dagger$ ).
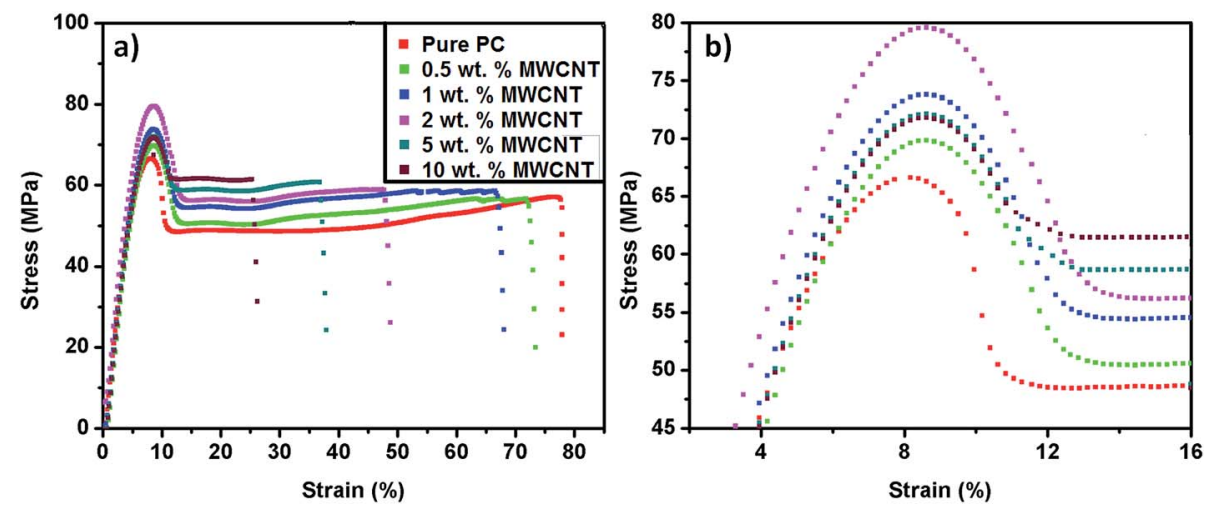

Fig. 2 Tensile stress-strain curves of: (a) MWCNT/PC composites (b) zoom on stress-strain curve. 

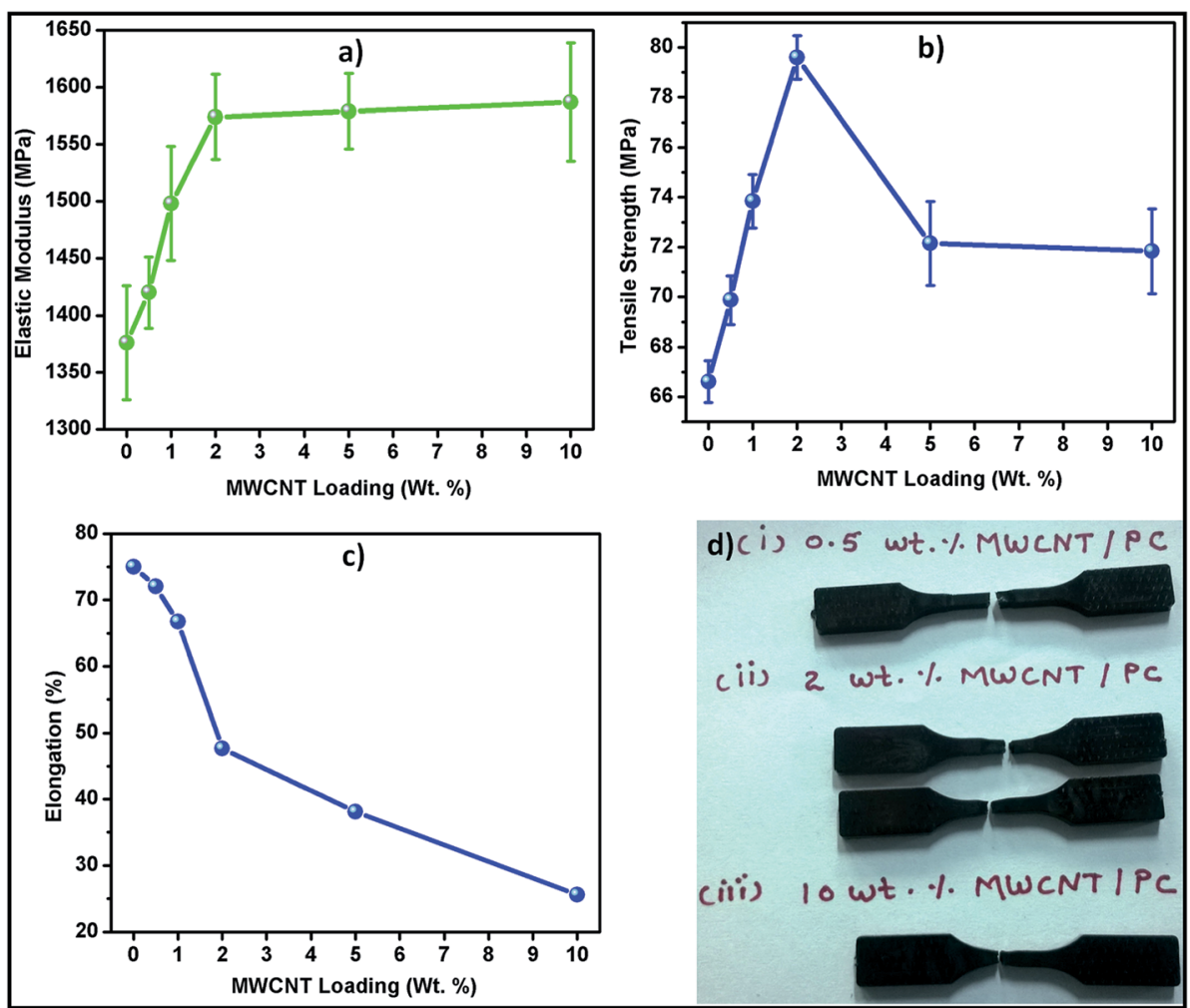

Fig. 3 Tensile property: (a) elastic modulus, (b) tensile strength, (c) elongation with respect to the MWCNT loading in PC matrix and (d) failed composite samples of: (i) 0.5 wt\% MWCNT/PC composite, (ii) 2 wt $\%$ MWCNT/PC composite and (iii) 10 wt\% MWCNT/PC composite.

Flexural properties of MWCNT/PC composite. In flexural test, probability of composite samples to break without plastic deformation escalates with MWCNT loading. Fig. 4 shows the effect of MWCNTs on the flexural properties. Both modulus and strength increase with MWCNT loading. Enhancement in flexural modulus was $12.9 \%$ (2419 MPa) for $10 \mathrm{wt} \%$ and $11.9 \%$ (2398 MPa) for $2 \mathrm{wt} \%$ MWCNT loading over the pure PC (2143 $\mathrm{MPa})$. Increase in values of flexural modulus was consistent for 5 and $10 \mathrm{wt} \% \mathrm{MWCNT} / \mathrm{PC}$ composite which suggest the dominating effect of MWCNT. On the other hand, enhancement in flexural strength was $10.9 \%$ (106.5 MPa) for $10 \mathrm{wt} \%$ MWCNT and $14.6 \%(110 \mathrm{MPa})$ at $2 \mathrm{wt} \%$ MWCNT loading over the pure PC (96 MPa) (Table S2 in ESI $\dagger$ ). Fig. 4(c) shows the plot between flexural strains vs. MWCNT loading. It suggests that the presence of higher amount of MWCNT in composite lead to lower strain at the yielding point.

The homogeneous dispersion of CNTs in polymer matrix is an important criterion for significant enhancement in the properties of the composite materials. Any aggregation creates defects in the structure which deteriorate the mechanical properties of the composite materials. Fig. 5(a) shows the SEM image of $2 \mathrm{wt} \% \mathrm{MWCNT} / \mathrm{PC}$ composite slice where individual MWCNT is seen just like a dot which confirms the proper dispersion of MWCNT in the PC matrix. Fig. 5(b and c) show the SEM image of cross section of the fractured surface of $2 \mathrm{wt} \%$ MWCNT/PC composites also showing the uniform dispersion of MWCNT. A coating of PC is visible on individual tubes (marked by a circle in Fig. 5(c)) suggests good wetting of CNTs by PC and is also a good indicator of strong interaction between CNTs and the PC.

For further understanding of the mechanism of enhancement in the mechanical properties, HRTEM studied were carried out. Fig. 6(a and b) show the HRTEM micrograph of both 2 and $10 \mathrm{wt} \%$ MWCNT/PC composites. By carefully analyzing the HRTEM micrographs, we observed that $2 \mathrm{wt} \%$ MWCNT sample shows higher dispersion relative to $10 \mathrm{wt} \%$ MWCNT. Interaction between polymer and MWCNT is less intense in comparison to the cohesion force between MWCNTs which enhances the probability of agglomeration inside the composite for $10 \mathrm{wt} \%$ MWCNTs.

At adequate amount of MWCNT ( $2 \mathrm{wt} \%$ ), MWCNTs demonstrate wetting effect with the host polymer as well as better alignment inside the composite samples (Fig. 6(c)) which shall enhance the composite's property further. At higher loading of MWCNT $(10 \mathrm{wt} \%)$ the probability of agglomeration also increases due to the higher cohesive force between the MWCNTs as clear shown in the HRTEM micrograph (Fig. 6(b)). MWCNTs contribute towards the enhancement of mechanical property by taking external load as can be seen in Fig. 6(d).

\section{Raman spectroscopy}

Raman spectroscopy analysis was carried out to investigate the interaction between MWCNT and PC matrix in the composites. Raman spectrum of polycarbonate composites are shown in Fig. 7. Incorporation of MWCNT lead to suppression of PC 

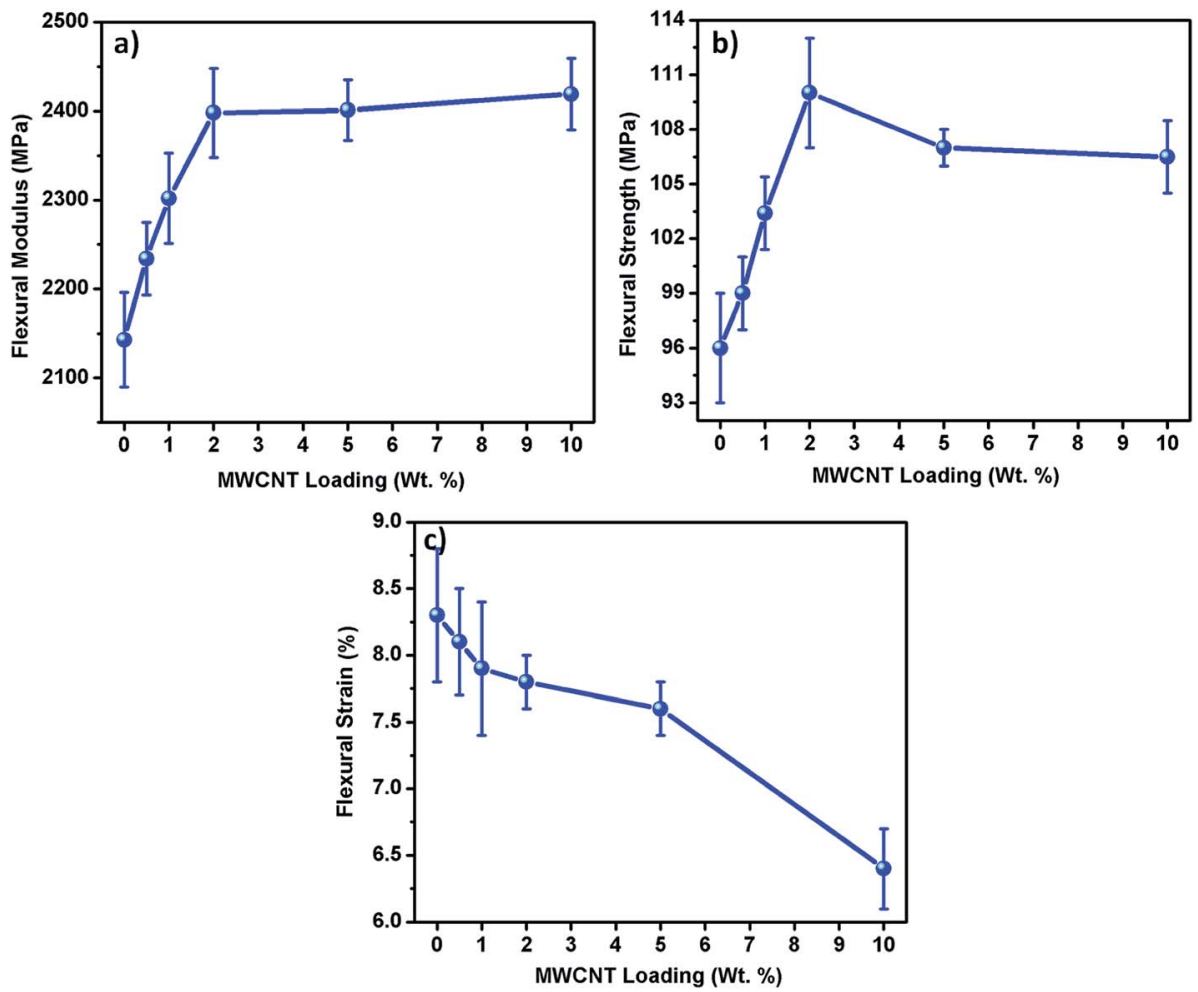

Fig. 4 Flexural property: (a) flexural modulus, (b) flexural strength and (c) flexural strain curve with respect to the MWCNT loading in PC matrix.
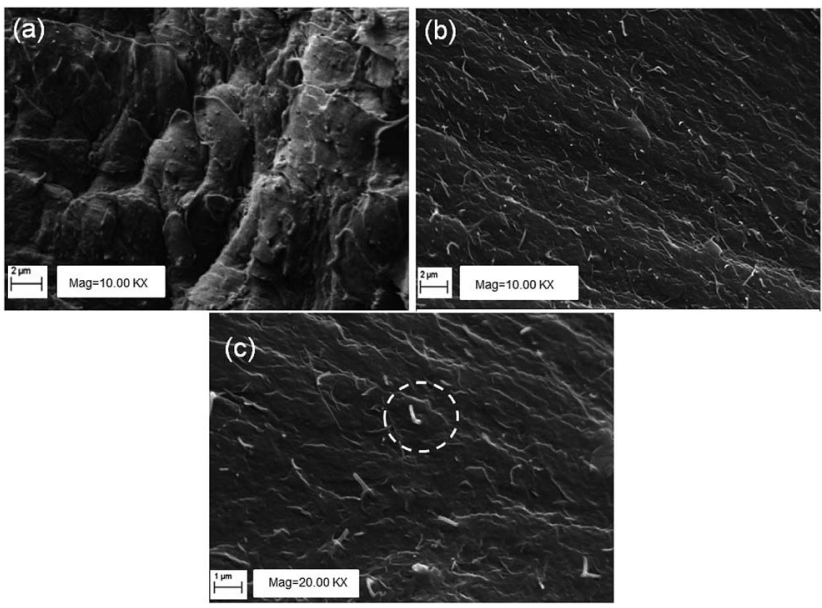

Fig. 5 SEM image of (a) 2 wt\% MWCNT/PC composite slice and (b and c) cross-section of fracture surface of 2 wt\% MWCNT/PC composite at low and high magnification respectively.

peaks. As evident from Fig. 7(c and d), incorporation of MWCNT lead to duplet formation which is the characteristic peak of PC and is situated at $1603.6 \mathrm{~cm}^{-1}$. Duplet peak situated at the higher wavelength shows shifting from $1603.6 \mathrm{~cm}^{-1}$ (pure PC) to $1596.8 \mathrm{~cm}^{-1}$ (for $2 \mathrm{wt} \%$ ) and then toward the higher wavelength at $1602.74 \mathrm{~cm}^{-1}$ for $10 \mathrm{wt} \%$ MWCNT/PC composite (see Fig. $7(\mathrm{~d}$ and e)). This shifting in peaks reveals the interaction between PC and MWCNT. ${ }^{37}$ The shifting of peak for composites with respect to the incorporated MWCNT are enumerated in
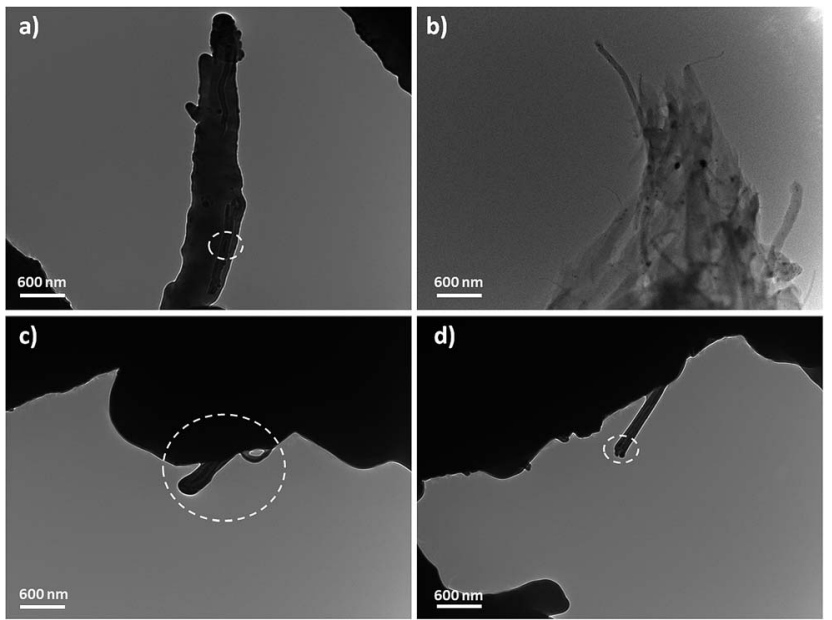

Fig. 6 TEM images of: (a) 2 wt\% (b) 10 wt\% MWCNT/PC composite, (c) carbon nanotubes coated with PC polymer and (d) fractured MWCNT in $2 \mathrm{wt} \%$ MWCNT/PC composite.

table in the inset of Fig. 7(e). The obtained shifting pattern of Raman peak is in good agreement with the acquired mechanical data.

\section{Electrical conductivity}

In addition to outstanding mechanical properties of CNT, its electrical properties are also good. Therefore, the electrical conductivity of MWCNT/PC composite is studied. Fig. 8 shows the effect of MWCNT loading on electrical conductivity. 

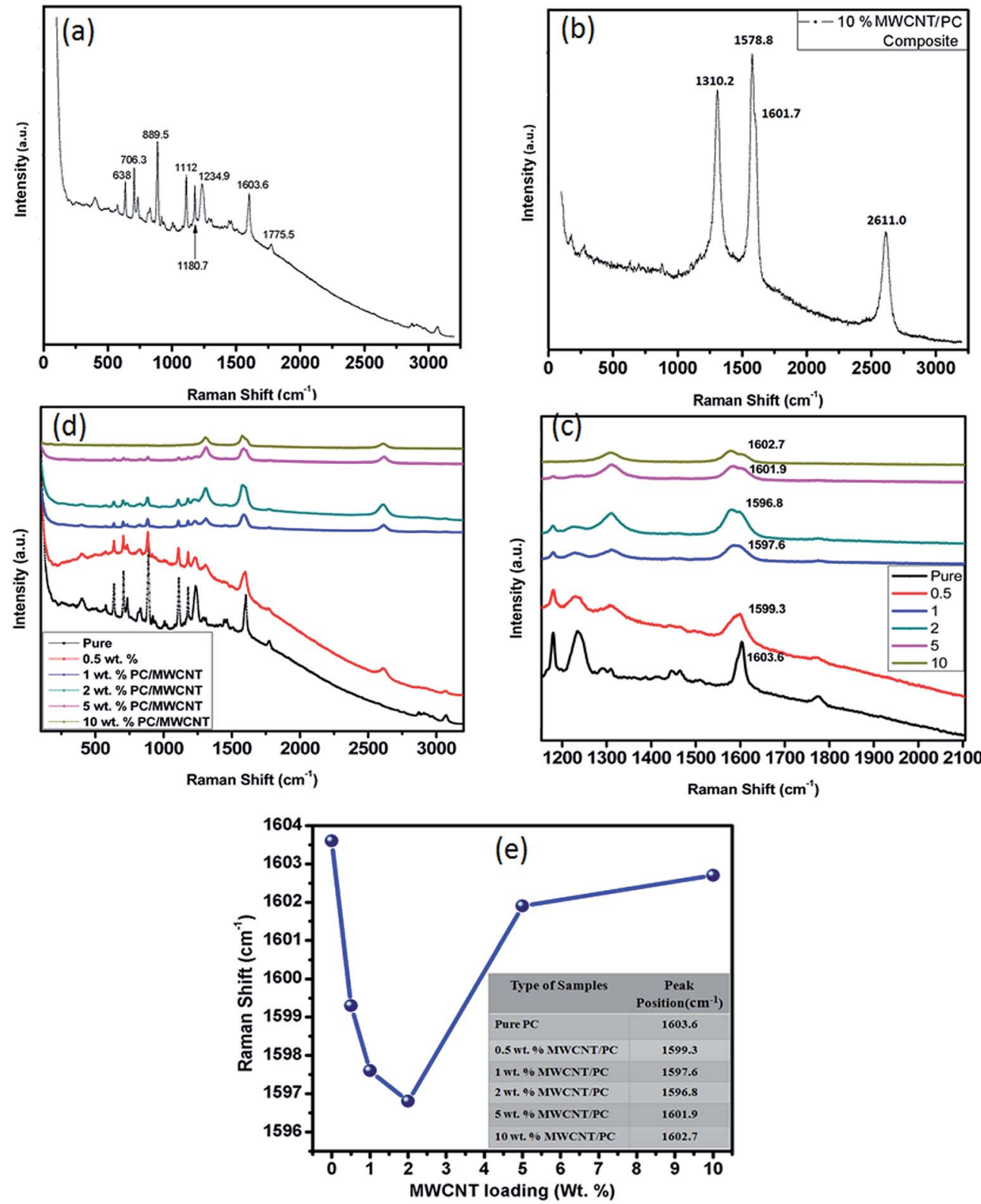

Fig. 7 Raman spectra of (a) pure polycarbonate, (b) 10 wt\% MWCNT/PC composite, (c) Raman spectra for different concentration of MWCNT loading in polymer matrix, (d) shifting in characteristic peak and (e) Raman shift with respect to MWCNT loading and inset shows table for peak position.

Incorporation of small amount of MWCNT lead to upsurge in electrical conductivity. There is a sizeable amount of increase in the conductivity (of the order of $7.9 \times 10^{-6} \mathrm{~S} \mathrm{~cm}^{-1}$ (for $2 \mathrm{wt} \%$ )) even after the constriction resistance as well as higher current dissipation at MWCNT contacts. It gives information about the presence of percolation threshold below 2 wt $\%$ MWCNT loading. Maximum electrical conductivity obtained for $10 \mathrm{wt} \%$ MWCNT/PC composite is of order of $1.3 \times 10^{-2} \mathrm{~S} \mathrm{~cm}^{-1}$. Conductivity results are stated in the Table S3 (see ESI $\dagger$ ). Using the percolation theory, dependence of electrical conductivity on filler amount can also be predicted using the scaling law:

$$
\sigma=\sigma_{0}\left(p-p_{0}\right)^{t}
$$

where $\sigma$ is conductivity of the composite, $\sigma_{0}$ is a constant, $p$ is the weight fraction of MWCNT, $p_{0}$ is the percolation threshold, and $t$ is the critical exponent. ${ }^{38}$

The equation can also be written by taking logarithm of both sides:

$$
\log (\sigma)=\log \left(\sigma_{0}\right)+t \log \left(p-p_{0}\right)
$$

By taking the linear regression of $\log (\sigma) v s . \log \left(p-p_{0}\right)$ both percolation threshold and critical exponent can be evaluated. At percolation threshold, a physical path is formed inside the composite which serve as a pathway for the charge carriers to stream. Both lower percolation threshold and higher critical 


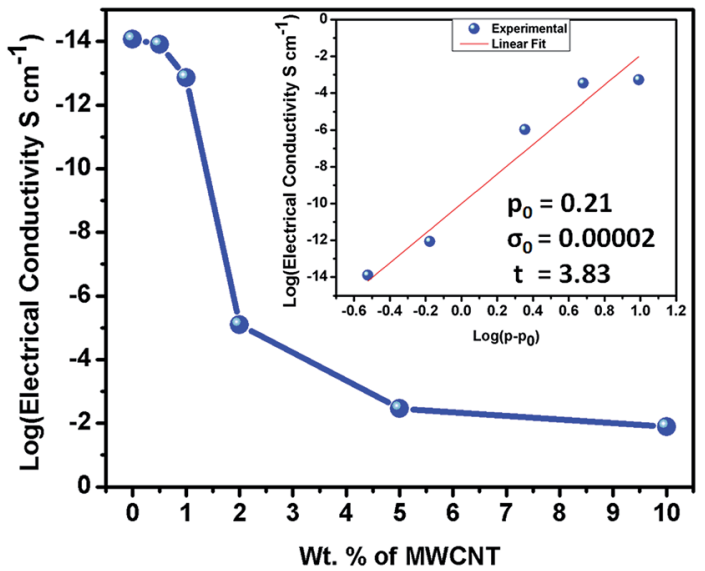

Fig. 8 Variation in electrical conductivity with MWCNT loading in PC matrix.

exponent value are an indicator of homogenous filler dispersion as described somewhere else. ${ }^{39}$

Inset of Fig. 8 shows the fitting of electrical conductivity data into the scaling law. Parameter values obtained from the fitting are: $p_{0}=0.21 \mathrm{wt} \%, \sigma_{0}=0.00002 \mathrm{~S} \mathrm{~cm}^{-1}$, and $t=3.83$. The $\log (\sigma)$ versus $\log \left(p-p_{0}\right)$ plot shows a straight line displaying an excellent fit to the data. For the composite material the percolation threshold was $0.21 \mathrm{wt} \%$ for MWCNT loading. The value of critical exponent $(t)$ obtained from the fit is in good agreement with estimated value from the percolation theory for a $3 \mathrm{D}$ conducting network in an insulating polymer matrix. ${ }^{38}$

\section{EMI shielding properties of MWCNT/PC composites}

These composites have electrical conductivity in the required range for EMI shielding. ${ }^{40}$ Therefore, EMI shielding of these composites were studied. The EMI shielding is a direct outcome of reflection, multiple internal reflection and absorption of incident electromagnetic wave (EMW) by the composite material. The presence of charge carriers leads to EMW reflection via reflection mechanism. EMW penetrate through the material and get attenuated via the absorption. Absorption loss is more important for magnetic field of EMW than electric field. Therefore electric field of EMW is mostly reflected at the interface. ${ }^{41}$ Penetrated EMWs lead to formation of magnetic and electrical dipole in the material which can attenuate the electromagnetic field. Attenuation effect due to the dipoles is lesser than the mobile charge carriers present in the shielding material. In composite, carriers come from the MWCNTs. There are limited studies on EMI shielding properties of MWCNT/PC composites. $^{30}$ These limited studies showed that EMI shielding properties of composite get enhanced with incorporation of MWCNT due to increased electrical conductivity. In most of the studies the main dominating factor reported for EMI shielding is absorption. ${ }^{2,16,42-44}$
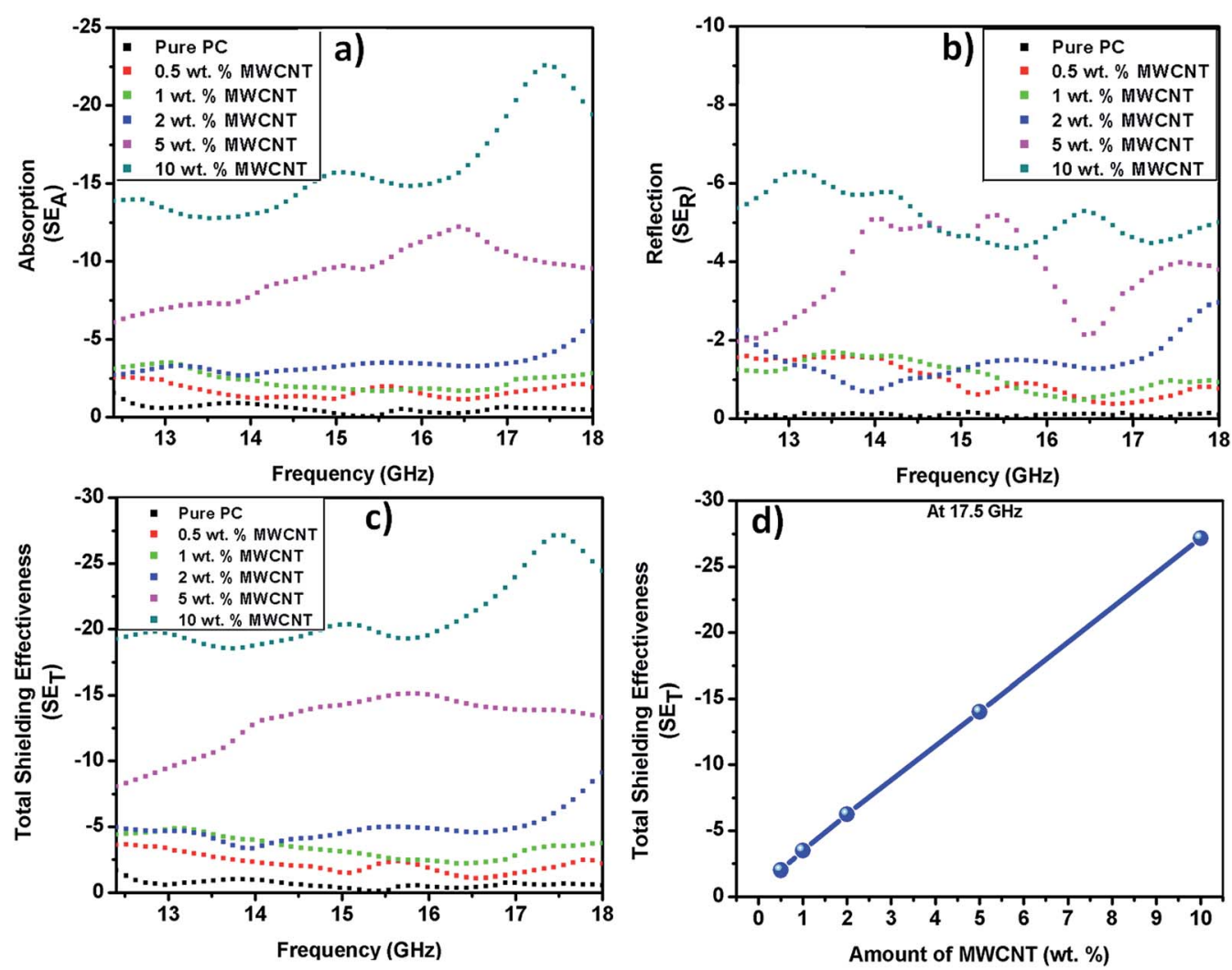

Fig. 9 EMI (a) absorption, (b) reflection, (c) total shielding effectiveness as a function of frequency and (d) plot of total shielding effectiveness $\left(\mathrm{SE}_{\mathrm{T}}\right)$ vs. amount of MWCNT in polymer matrix. 
EMI shielding properties of composites with different loading of MWCNTs are shown in Fig. 9. It is evident that absorption loss is the primary mechanism for EMI shielding. In order to further explore the $\mathrm{SE}_{\mathrm{T}}$, it was resolved into the $\mathrm{SE}_{\mathrm{A}}$ and $\mathrm{SE}_{\mathrm{R}}$, as shown in Fig. 8(a and b), respectively. Several equations have been used in order to find out the contribution of absorption and reflection of EMI SE. Shielding by both absorption and reflection is given by: ${ }^{45}$

$$
\begin{gathered}
\mathrm{SE}_{\mathrm{A}}=K t(f \mu \sigma)^{1 / 2} \\
\mathrm{SE}_{\mathrm{R}}=108-10 \log _{10}(f \mu / \sigma)
\end{gathered}
$$

where $\mathrm{SE}_{\mathrm{A}}$ and $\mathrm{SE}_{\mathrm{R}}$ are reflection and absorption shielding effectiveness, respectively; $K$ is constant, $t$ is the shielding material thickness; $f$ is frequency; $\mu$ is magnetic permeability and $\sigma$ is electrical conductivity. From the equations it is evident that both absorption and reflection part of SE increases with increase in the electrical conductivity. Loss due to reflection decreases with increase in frequency but for the absorption it is just the opposite. The rate of increase of $\mathrm{SE}_{\mathrm{A}}$ is much greater than $\mathrm{SE}_{\mathrm{R}}$ which is a direct consequence of square and logarithmic electrical conductivity dependence of $\mathrm{SE}_{\mathrm{R}}$ and $\mathrm{SE}_{\mathrm{A}}$, respectively. ${ }^{45}$ Fig. 9 show that $\mathrm{SE}_{\mathrm{A}}$ and $\mathrm{SE}_{\mathrm{R}}$ increase up to 22.56 $\mathrm{dB}$ and $6.28 \mathrm{~dB}$, respectively over the pristine $\mathrm{PC}$ in the whole $\mathrm{Ku}$ band $(12-18 \mathrm{GHz})$.

Attenuation in EMW increases with further incorporation of MWCNTs. Results from Fig. 9(c) show that pure polycarbonate is nearly transparent to the microwave radiation $\left(\mathrm{SE}_{\mathrm{T}} \approx-0.56\right.$ $\mathrm{dB})$. With increase in MWCNT loading a systematic enhancement in total EMI shielding $\left(\mathrm{SE}_{\mathrm{T}}\right)$ is observed and $-27.2 \mathrm{~dB} \mathrm{SE}_{\mathrm{T}}$ value was achieved for the $10 \mathrm{wt} \% \mathrm{MWCNT} / \mathrm{PC}$ composite (Table S4, see ESI†). From Fig. 9(d), it is evident that the rate of total loss is almost constant with further increase in MWCNT (at frequency of $17.5 \mathrm{GHz}$ ). Increase in EMI shielding with MWCNT loading can be linked with the formation of conductive network within the electrically insulating polymer matrix and availability of larger no. of charges to interact with the incoming EMW. Better dispersion of MWCNTs allows formation of percolation network at lower concentration which enhances the electrical properties of composite. This results into higher EMI shielding up to $-27.2 \mathrm{~dB}$ at $10 \mathrm{wt} \%$ MWCNT. The observed EMI shielding herein crossed the limit $(-20$ to $-30 \mathrm{~dB})$ of commercial applications, which suggests that these nanocomposites are promising EMI shielding material with improved mechanical properties.

\section{Conclusion}

MWCNT/polycarbonate composites were prepared using micro twin screw extruder with back flow channel followed by injection molding which allowed uniform distribution of MWCNT in polymer matrix. SEM and TEM images confirm the uniform dispersion of MWCNTs in polycarbonate matrix. This results in significant enhancement in the tensile and flexural properties. It was found that upto 2 wt MWCNT\% loading, tensile and flexural strength improved by $19.6 \%$ and $14.6 \%$ respectively.
Beyond this loading there was slight decline in the strength but the values were still higher than pure polycarbonate matrix. Additionally, maximum electrical conductivity value of $1.27 \times$ $10^{-2} \mathrm{~S} \mathrm{~cm}^{-1}$ was achieved for $10 \mathrm{wt} \%$ loading which helped us to achieve high EMI SE for such material up to $-27.2 \mathrm{~dB}$ in $\mathrm{Ku}$ band $(12.4-18 \mathrm{GHz})$ which is most frequently used for the satellite communication and VSAT systems. The observed EMI shielding herein crossed limit $(-20$ to $-30 \mathrm{~dB})$ for commercial applications, which suggests that these nanocomposites are promising EMI shielding material with improved mechanical properties.

\section{Acknowledgements}

Authors wish to express gratitude to Prof. R. C. Budhani, Director, CSIR-National Physical Laboratory, New Delhi, India for his keen interest in the work. Authors are thankful to Mrs Shaveta Sharma for mechanical properties measurement. Authors are also thankful to Mr Avanish Pratap Singh and Dr S. K. Dhawan for electrical conductivity and EMI shielding measurements and Mr J. Tawale for SEM measurements. The study was carried out under the CSIR-network project (PSC0109).

\section{References}

1 D. Chung, Carbon, 2001, 39, 279-285.

2 Z. Liu, G. Bai, Y. Huang, Y. Ma, F. Du, F. Li, T. Guo and Y. Chen, Carbon, 2007, 45, 821-827.

3 R. S. Ruoff, D. Qian and W. K. Liu, C. R. Phys., 2003, 4, 9931008.

4 A. Sears and R. Batra, Physical Review B: Condensed Matter and Materials Physics, 2004, 69, 235406.

5 M. S. Dresselhaus, G. Dresselhaus and P. C. Eklund, Science of fullerenes and carbon nanotubes: their properties and applications, Academic press, 1996.

6 S. Iijima, Nature, 1991, 354, 56-58.

7 Y. Sung, M. Han, K. Song, J. Jung, H. Lee, C. Kum, J. Joo and W. Kim, Polymer, 2006, 47, 4434-4439.

8 M. S. Shaffer and A. H. Windle, Adv. Mater., 1999, 11, 937941.

9 J. Sandler, M. Shaffer, T. Prasse, W. Bauhofer, K. Schulte and A. Windle, Polymer, 1999, 40, 5967-5971.

10 P. Pötschke, T. Fornes and D. Paul, Polymer, 2002, 43, 32473255.

11 P. Pötschke, M. Abdel-Goad, I. Alig, S. Dudkin and D. Lellinger, Polymer, 2004, 45, 8863-8870.

$12 \mathrm{M}$. Abdel-Goad and P. Pötschke, J. Non-Newtonian Fluid Mech., 2005, 128, 2-6.

13 H. T. Ham, C. M. Koo, S. O. Kim, Y. S. Choi and I. J. Chung, Macromol. Res., 2004, 12, 384-390.

14 W. K. Park, J. H. Kim, S.-S. Lee, J. Kim, G.-W. Lee and M. Park, Macromol. Res., 2005, 13, 206-211.

15 S. Barrau, P. Demont, A. Peigney, C. Laurent and C. Lacabanne, Macromolecules, 2003, 36, 5187-5194.

16 H. Kim, K. Kim, C. Lee, J. Joo, S. Cho, H. Yoon, D. Pejaković, J. Yoo and A. Epstein, Appl. Phys. Lett., 2004, 84, 589-591. 
17 P. Jindal, S. Pande, P. Sharma, V. Mangla, A. Chaudhury, D. Patel, B. P. Singh, R. B. Mathur and M. Goyal, Composites, Part B, 2013, 45, 417-422.

18 S. Pande, B. P. Singh and R. B. Mathur, in Polymer Nanotube Nanocomposites: Synthesis, Properties, and Applications, 2nd edn, 2014, pp. 333-364.

19 Z. Jin, K. Pramoda, S. H. Goh and G. Xu, Mater. Res. Bull., 2002, 37, 271-278.

20 R. Haggenmueller, H. Gommans, A. Rinzler, J. E. Fischer and K. Winey, Chem. Phys. Lett., 2000, 330, 219-225.

21 P. Pötschke, H. Brünig, A. Janke, D. Fischer and D. Jehnichen, Polymer, 2005, 46, 10355-10363.

22 L. Chen, X.-J. Pang and Z.-L. Yu, J. Mater. Sci. Eng. A, 2007, 457, 287-291.

23 T. Fornes, J. Baur, Y. Sabba and E. Thomas, Polymer, 2006, 47, 1704-1714.

24 J. A. King, M. D. Via, J. A. Caspary, M. M. Jubinski, I. Miskioglu, O. P. Mills and G. R. Bogucki, J. Appl. Polym. Sci., 2010, 118, 2512-2520.

25 A. Eitan, F. Fisher, R. Andrews, L. Brinson and L. Schadler, Compos. Sci. Technol., 2006, 66, 1162-1173.

26 C. K. Kum, Y.-T. Sung, M. S. Han, W. N. Kim, H. S. Lee, S.-J. Lee and J. Joo, Macromol. Res., 2006, 14, 456-460.

27 S. Pande, A. Chaudhary, D. Patel, B. P. Singh and R. B. Mathur, RSC Adv., 2014, 4, 13839-13849.

28 T. Hiramoto, T. Terauchi and J. Tomibe, Electrical Overstress/ Electrostatic Discharge Symp. Proc., ESD Assoc., Rome, New York, USA ESD, 1998, pp. 18-21.

29 N. Li, Y. Huang, F. Du, X. He, X. Lin, H. Gao, Y. Ma, F. Li, Y. Chen and P. C. Eklund, Nano Lett., 2006, 6, 1141-1145.
30 M. Arjmand, M. Mahmoodi, G. A. Gelves, S. Park and U. Sundararaj, Carbon, 2011, 49, 3430-3440.

31 H. Wang, G. Wang, W. Li, Q. Wang, W. Wei, Z. Jiang and S. Zhang, J. Mater. Chem., 2012, 22, 21232-21237.

32 R. Mathur, S. Chatterjee and B. Singh, Compos. Sci. Technol., 2008, 68, 1608-1615.

33 Y. Zhou and P. Mallick, J. of Compos., 2014, 2014, 846962.

34 R. Tolokan and J. Nablo, Plast. Eng., 1985, 41, 31-34.

35 Y. Man, Z. Li and Z. Zhang, Mater. Trans., 2009, 50, 1355.

36 P. Garg, B. P. Singh, G. Kumar, T. Gupta, I. Pandey, R. Seth, R. Tandon and R. B. Mathur, J. Polym. Res., 2011, 18, 13971407.

37 L. Bokobza and J. Zhang, eXPRESS Polym. Lett., 2012, 6, 601608.

38 A. Aharony and D. Stauffer, Introduction to percolation theory, Taylor \& Francis, 2003.

39 M. Weber and M. R. Kamal, Polym. Compos., 1997, 18, 711725.

40 B. P. Singh, V. Choudhary, P. Saini, S. Pande, V. N. Singh and R. B. Mathur, J. Nanopart. Res., 2013, 15, 1-12.

41 K. L. Kaiser, Electromagnetic shielding, CRC Press, 2005.

42 R. B. Mathur, S. Pande, B. P. Singh and T. L. Dhami, Polym. Compos., 2008, 29, 717-727.

43 S. Pande, B. Singh, R. Mathur, T. Dhami, P. Saini and S. Dhawan, Nanoscale Res. Lett., 2009, 4, 327-334.

44 B. P. Singh, P. Saini, T. Gupta, P. Garg, G. Kumar, I. Pande, S. Pande, R. K. Seth, S. K. Dhawan and R. B. Mathur, J. Nanopart. Res., 2011, 13, 7065-7074.

45 L. Olmedo, P. Hourquebie, F. Jousse and H. Nalwa, Handbook of organic conductive molecules and polymers, 1997, vol. 3 . 